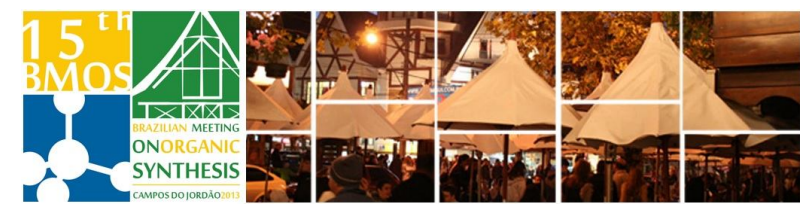

\title{
Multicomponent catalytic Mannich Reaction: a methodological study with lawsone
}

\author{
Fiorot, R. G. ${ }^{1,2 \star}$ Allochio Filho, J. F.;1,2 Greco, S. G.; ${ }^{1,2^{*}}$ Lacerda Jr., V.; ${ }^{1,2}$ dos Santos, \\ R. B. ${ }^{1,2}$ and de Castro, E. V. R. ${ }^{2}$ \\ ${ }^{1}$ LSO\&M - Laboratório de Síntese Orgânica e Medicinal. Universidade Federal do Espírito Santo. Vitória, Brazil. \\ ${ }^{2}$ NCQP - Núcleo de Competências em Química de Petróleo. Universidade Federal do Espírito Santo. Vitória, Brazil. \\ *e-mail: fiorot.rodolfo@gmail.com; sandrogreco.ufes@gmail.com
}

Keywords: Mannich, multicomponent reaction, lawsone.

\section{INTRODUCTION}

The multicomponent one-pot synthesis has received great importance due to its wide range of applications in pharmaceutical chemistry and combinatorial libraries for drug discovery. ${ }^{1}$

The Mannich reaction is a classical method for the preparation of $\beta$-aminocarbonylated compounds from amine, aldehyde and an active $\mathrm{CH}$ bond, and it's one of the most important reaction in organic chemistry.

Our research group described the multicomponent Mannich reaction with lawsone and various aldehydes and amines in ethanol at room temperature, according to the procedure found in the literature with some modifications. ${ }^{2}$ It should be noticed that the reaction times ranged from 12 to 48 hours, depending on the aldehyde and the amine used. Dabiri and co-workers published Mannich reaction in aqueous medium, under reflux, using $\mathrm{InCl}_{3}$ as catalyst where reaction times varied from 4 to 7.5 hours. $^{3}$

\section{RESULTS AND DISCUSSION}

Initially, the three-component reaction of 2-hydroxynaphthoquinone (lawsone), p-nitrobenzaldehyde and p-nitroaniline, as a simple model substrate, was investigated to establish the feasibility of the strategy and optimize the reaction conditions (Scheme 1). At first, different solvent were screened in order to choose the best one in terms of yield and reaction time (Table 1).

Scheme 1. Model for the multicomponent Mannich reaction optimization.

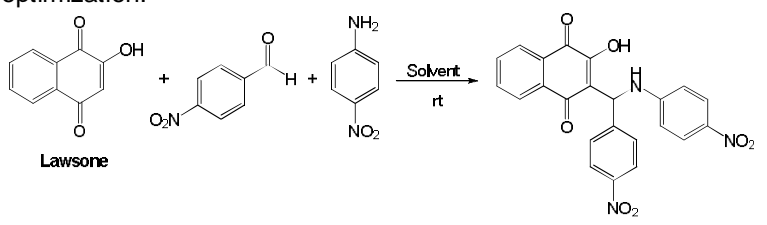

Table 1. Model reaction and solvents screening.

\begin{tabular}{cccc}
\hline Entry & Solvent/Volume & Time (h) & Yield (\%) \\
\hline 1 & $\mathrm{EtOH}(10 \mathrm{~mL})$ & 24 & 82 \\
\hline 2 & $\mathrm{H}_{2} \mathrm{O}(5 \mathrm{~mL})$ & 26 & 84 \\
\hline 3 & $\mathrm{CH}_{3} \mathrm{CN}(3 \mathrm{~mL})$ & 6 & 98 \\
\hline 4 & $\mathrm{Et}_{2} \mathrm{O}(4 \mathrm{~mL})$ & 26 & 87 \\
\hline 5 & Toluene $(4 \mathrm{~mL})$ & 26 & 73 \\
\hline
\end{tabular}

Subsequently, a study was conducted with some Brönsted-Lowry and Lewis acids to assess its effectiveness as catalysts for the model reaction (Table 2 ). The amount of $20 \mathrm{~mol} \%$ of catalyst was initially established as a standard.

Table 2. Model reaction and catalyst screening in $\mathrm{CH}_{3} \mathrm{CN}$.

\begin{tabular}{cccc}
\hline Entry & Catalyst & Time (h) & Yield (\%) \\
\hline 1 & - & 6 & 60 \\
\hline 2 & $\mathrm{Fe}_{2}\left(\mathrm{SO}_{4}\right)_{3} \cdot \mathrm{xH}_{2} \mathrm{O}$ & 2 & 66 \\
\hline 3 & $\mathrm{AlCl}_{3} \cdot 6 \mathrm{H}_{2} \mathrm{O}$ & 0.8 & 84 \\
\hline 4 & $\mathrm{CF}_{3} \mathrm{CO}_{2} \mathrm{H}$ & 0.8 & 94 \\
\hline 5 & $p-\mathrm{TsOH}$ & 0.8 & 98 \\
\hline
\end{tabular}

Based in these results, the system with $\mathrm{CH}_{3} \mathrm{CN}$ as solvent and $p$-TsOH as catalyst showed to be the more efficient to the multicomponent Mannich reaction. With conditions optimized, reaction with lawsone, pyrrolidine as amino compound and aromatic aldehydes was investigated (Scheme 2).

Scheme 2. Multicomponent Mannich reaction derived from lawsone and pirrolydine.

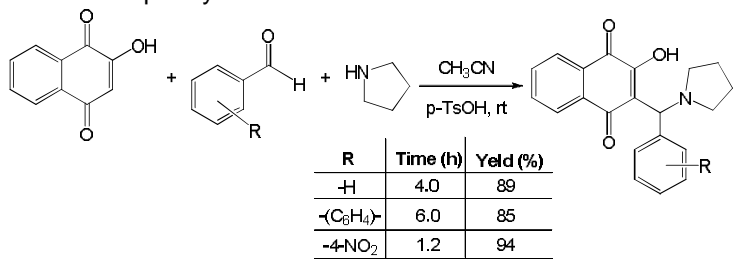

CONCLUSION

The multicomponent Mannich reaction is a good methodology to synthesize several $\beta$ aminocarbonylated compounds derived from lawsone. Our methodology (acetonitrile as solvent and $p-\mathrm{TsOH}$ as catalyst) showed to be excellent in terms of reaction time (0.8-6.0 h) and yield (85-94\%).

\section{ACKNOWLEDGEMENTS}

We thank to FAPES, CAPES, CNPq and LabPetroDQUI/UFES for financial support.

\section{REFERENCES}

1Dömling, A.; Ugi, I. Angew. Chem., Int. Ed. 2000, 39, 3168;

${ }^{2}$ Greco, S. J.; Neves, A. P.; Barbosa, C. C.; Vargas, M. D.; Visentin, L. C.; Pinheiro, C. B.; Mangrich, A. S.; Barbosa, J. P.; da Costa, G. L. Journal Braziliam Chemical Society, 2009, 20, 712.

${ }^{3}$ Dabiri, M.; Tisseh, Z. N.; Bazgir, A. Dyes and Pigments, 2011, 89,63. 